Biotechnology

for Biofuels

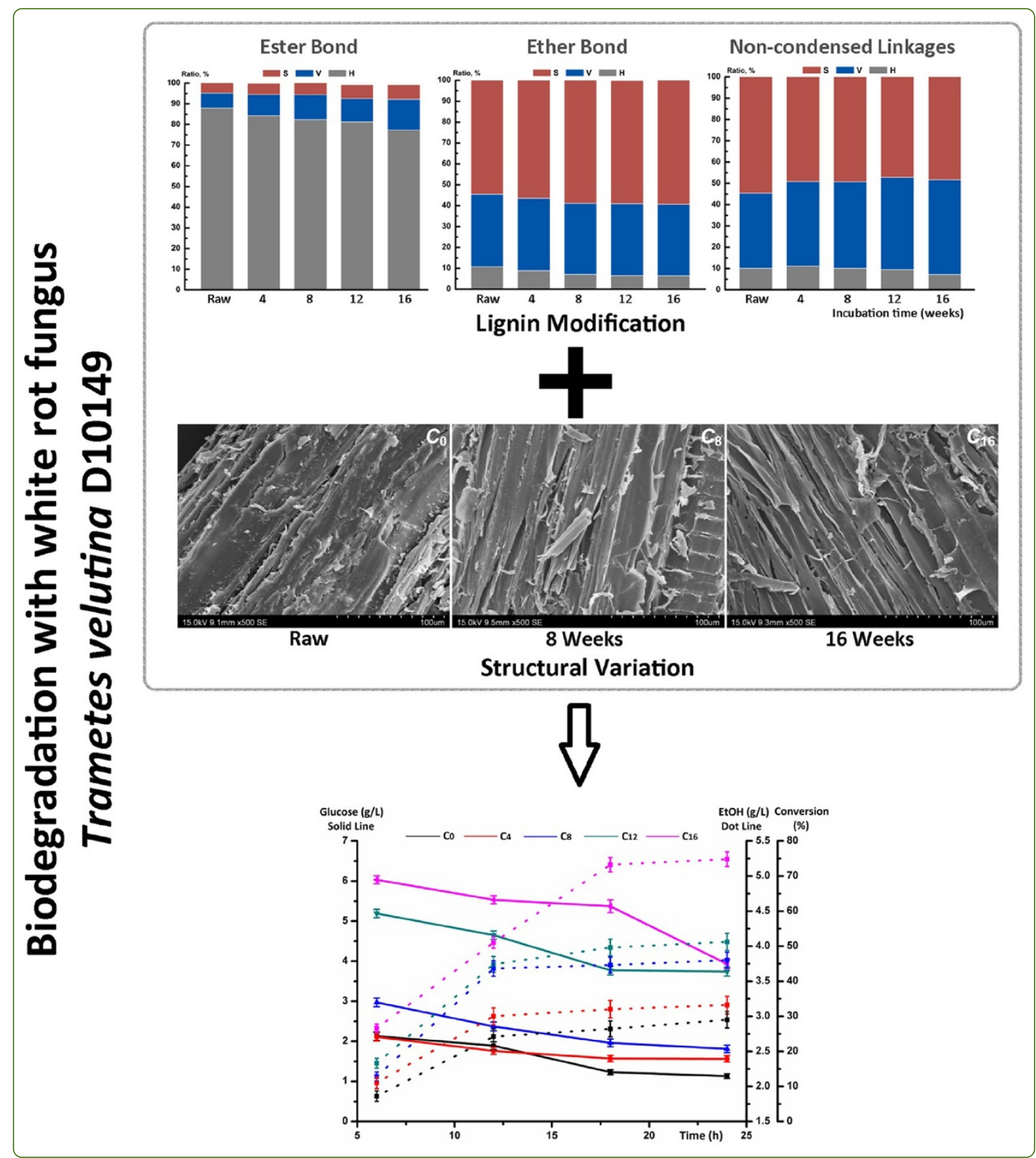

\title{
Structural evaluation and bioethanol production by simultaneous saccharification and fermentation with biodegraded triploid poplar
}

Wang et al. 


\title{
Structural evaluation and bioethanol production by simultaneous saccharification and fermentation with biodegraded triploid poplar
}

\author{
Kun Wang ${ }^{1}$, Haiyan Yang ${ }^{1}$, Wei Wang ${ }^{2}$ and Run-cang Sun ${ }^{1,3^{*}}$
}

\begin{abstract}
Background: Pretreatment is a key step to decrease the recalcitrance of lignocelluloses and then increase the digestibility of cellulose in second-generation bioethanol production. In this study, wood chips from triploid poplar were biopretreated with white rot fungus Trametes velutina D10149. The effects of incubation duration on delignification efficiency and structural modification of cellulose were comparably studied, as well as the digestibility of cellulose by simultaneous saccharification and fermentation (SSF).

Results: Although microbial pretreatments did not significantly introduce lignin degradation, the data from SSF exhibited higher cellulose conversion (21-75\% for biopretreated samples for 4-16 weeks) as compared to the untreated poplar (18\%). In spite of the essential maintain of crystallinity, the modification of lignin structure during fungal treatment undoubtedly played a key role in improving cellulose bioconversion rates. Finally, the ethanol concentration of $5.16 \mathrm{~g} / \mathrm{L}$ was detected in the fermentation broth from the cellulosic sample biodegraded for 16 weeks after $24 \mathrm{~h}$ SSF, achieving $34.8 \%$ cellulose utilization in poplar.

Conclusion: The potential fungal pretreatment with Trametes velutina D10149 was firstly explored in this study. It is found that the biopretreatment process had a significant effect on the digestibility of substrate probably due to the removal and unit variation of lignin, since the crystallinities of substrates were rarely changed. Additional investigation is still required especially to improve the selectivity for lignin degradation and optimize the digestibility of cellulose.
\end{abstract}

Keywords: Biodegradation, Lignocellulose, Simultaneous saccharification and fermentation, Bioethanol, Trametes velutina

\section{Background}

Lignocellulose is the major component of biomass, consisting of three types of polymers, cellulose, hemicelluloses and lignin that are strongly intermeshed and chemically bonded by non-covalent forces and by covalent cross-linkages [1]. Many scientific challenges remain in understanding the recalcitrancy of lignocelluloses, and numerous chemical and physical methods have been attempted to unlock lignin polymers from the cell wall complex [2-6]. However, these pretreatment processes are often limited by the lack of selectivity to the target

\footnotetext{
* Correspondence: rcsun3@bjfu.edu.cn

'Institute of Biomass Chemistry and Technology, Beijing Forestry University, Beijing, China

${ }^{3}$ State Key Laboratory of Pulp and Paper Engineering, South China University of Technology, Guangzhou, China

Full list of author information is available at the end of the article
}

component, together with high energy requirement, economical feasibility and environmental unfriendliness. Thus, effective, low-cost, and green biopretreatment under mild conditions and low energy consumption has manifested the superiority over the aforementioned chemical means [7].

Nature has created a mixture of enzymatic complexes, which are capable of opening the complex structure of lignin molecules by selectively cleaving the chemical bonds between the lignin units without using/releasing any environmentally harsh chemicals [8]. Thereby, it is considered to be an environmentally friendly process with its own advantages, including no chemicals, no required special reactor, no waste and no inhibitor to fermentation. In fact, biological pretreatment has long been studied in the pulping process to save energy, increase pulp quality and reduce environmental impacts [9]. White-rot fungi, as the

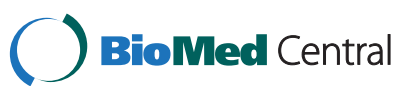


most promising microorganisms for selective lignin degradation, have been receiving extensive attention for biodelignification of lignocellulosic biomass. It has the ability to produce lignolytic enzymes, including manganese peroxidases (MnPs), lignin peroxidases (LiPs) and esterases (ESTRs) [10], as well as $\mathrm{H}_{2} \mathrm{O}_{2}$ generating enzyme systems (copper radical oxidases, aryl alcohol oxidases, glyoxal oxidases etc.), which play key roles during the lignin degradation/modification process [11,12]. Nowadays, several basidiomycetes such as Phanerochaete chrysosporium, Ceriporiopsis subvermispora, Phlebia subserialis, and Pleurotus ostreatus have been examined on different lignocellulosic substrate to evaluate their delignification efficiency. As known, most white-rot fungi simultaneously degrade carbohydrates (cellulose and hemicelluloses) and lignin, resulting in the homogeneous decay of the cell wall. Meanwhile, some species preferentially degrade lignin and part of hemicelluloses, dissolving the middle lamella and then creating the defibrillation effect. Due to the deconstruction of the impact matrix in biomass, the accessibility of cellulose for cellulase is improved and the production of sugars during bioconversion process is significantly enhanced [13-15]. Baba et al. reported that biopretreatment with white-rot fungi resulted in significantly higher sugar yield $(>35 \%)$ than untreated softwood (10.2\%) [16]. It was also reported that the enzymatic digestibilities of corn stover, which had been pretreated with Cyathus stercoreus and $P$. chrysosporium, were 3.75 and 1.26 times greater than that of untreated sample, respectively [17]. Different white rot fungus varies greatly in the relative rates, where the degradation of lignin and carbohydrates occur in lignocelluloses. Zhang et al. screened 34 kinds of white rot fungi and found only two isolates were suitable for the biopretreatment process [18]. Recently, a new fungus, Trametes velutina D10149, was isolated and identified in Institute of Microbiology, Beijing Forestry University. Thereby, it is necessary to investigate the biodegradation pattern and evaluate the pretreatment efficiency on bioethanol production by Trametes velutina D10149, in order to fully exploit the potential of this fungus.
In the present study, biological delignification of triploid poplar (Populus tomentosa Carr.) using white-rot fungus T. velutina D10149 was attempted. The methods of wet chemistry, X-ray diffraction (XRD), Fourier transform infrared (FTIR), and scanning electron microscopy (SEM) were applied to characterize and gain insights on the delignification process and structural modification of cellulose in lignocelluloses. The biological pretreatment was further evaluated by ethanol yield from bioconversion process, simultaneous saccharification and fermentation (SSF), which will better meet the requirement for $2^{\text {nd }}$ generation bio-ethanol production.

\section{Results and discussion}

\section{Delignification process evaluation}

Lignification is considered to be a primary factor limiting the biodegradation of the cell wall by rumen microbes, and the knowledge of lignin content in the plant is consequently of primary importance to access the mechanisms involved in the inhibition of structural carbohydrate digestion. There are several analytical procedures for determining the lignin content, in which acetyl bromide soluble lignin (ABSL) method was considered to be a fast/convenient method and useful to predict in vitro digestibility [19]. As expected, the values of ABSL content were gradually decreased from $33.4 \%$ (control) to $24.6 \%$ as prolonging the incubation duration (Table 1). The maximum degree of the delignification was determined to be $61 \%$ (taking into account $46 \%$ weight loss of biodegraded sample for 16 weeks) in this work, which is in the same order of magnitude as pointed out by Zhang et al. [20]. Slight decrease of lignin was observed in the first 4 weeks incubation, and similar behavior has been found by Dinis et al. [21]. They detected the ligninolytic system of four white rot fungi, and noted that the maximums of manganese-dependent peroxidase (MnP), lignin peroxidase $(\mathrm{LiP})$ and laccase activities varied greatly at different fermentation times. Since lignin degradation depended on the synergistic role among the ligninolytic enzymes, it usually occurred later and gradually achieved the maximum degradation rate after 30 days [20].

Table 1 The content of lignin (ABSL, wt\%), infrared ratios and crystallinity indices of untreated and biopretreated cellulosic samples after different incubation time

\begin{tabular}{|c|c|c|c|c|c|}
\hline \multirow[t]{2}{*}{ Sample $^{a}$} & \multirow[t]{2}{*}{$\mathrm{ABSL}^{\mathrm{b}}$} & \multicolumn{2}{|c|}{ FT-IR } & \multirow[t]{2}{*}{$\mathrm{CrI}^{\mathrm{c}}$} & \multirow[t]{2}{*}{$\mathrm{Crl}$} \\
\hline & & LOI $\left(a_{1437} \mathrm{~cm}^{-1} / a_{899} \mathrm{~cm}^{-1}\right)$ & $\mathrm{TCl}\left(a_{1378} \mathrm{~cm}^{-1} / a_{2900} \mathrm{~cm}^{-1}\right)$ & & \\
\hline$C_{0}$ & 33.4 & 0.92 & 1.01 & 40.7 & 38.2 \\
\hline$C_{4}$ & 32.5 & 0.92 & 1.04 & 41.7 & 42.8 \\
\hline$C_{8}$ & 26.6 & 0.89 & 0.95 & 41.3 & 43.2 \\
\hline$C_{12}$ & 25.1 & 0.93 & 1.14 & 40.4 & 42.1 \\
\hline$C_{16}$ & 24.6 & 0.85 & 1.03 & 40.6 & 42.2 \\
\hline
\end{tabular}

${ }^{a} C_{x}$ represents the cellulosic residues, while the subscript $X(4,8,12$, and 16$)$ represents the different incubation weeks. $C_{0}$ was obtained without the biodegradation treatment as a control; ${ }^{b} \mathrm{ABSL}$ is abbreviation of acetyl bromide soluble lignin, and the standard deviations are less than $5 \%$; ${ }^{\mathrm{c}} \mathrm{Crl}$ was calculated based on the height of the peak corresponding to (002) lattice plane $\left(I_{002}\right)$ and the minimum between 110 and 002 lattice planes $\left(l_{\mathrm{am}}\right)$ as follow: $C_{r} l(\%)=\frac{l_{002}-l_{a m}}{l_{a m}} \times 100$, and the standard deviations are less than $2 \%$; ${ }^{\mathrm{d}} \mathrm{Cr}$ was calculated from the ratio of the crystalline area over the total area, where separation of crystalline (86-92 ppm) and amorphous (79-86 ppm) fractions were based on Guassian line shape function, and the standard deviations are less than $2 \%$. 
The ratios of phenolic composition in poplar cell wall are presented in Figure 1. Hydroxycinnamic acids, as bifunctional molecules with carboxylic and phenolic bonding sites, are usually involved in bridges through ester/ether linkages between lignin fragments and distinguished by treatment with alkali solution at different temperature and concentration. Obviously, the $\mathrm{H}$ unit predominated in ester bound cell well phenolics in all samples (Figure 1A), arranging from $88.0 \%$ to $77.3 \%$. These data are in accordance with the conclusion that the ester linkages in aspen wood lignin are mainly $p$-hydroxybenzoate groups [22]. As the incubation processed, the yields of the detectable phenolics were gradually decreased (Table 2), as well as the $\mathrm{H}$ unit proportion (Figure 1A). Although the biodegradation data for poplar were seldom involved, the release of hydroxycinnamic acids in several agroindustrial byproducts could be used as references. Dinis et al. reported that the decrease of esterified hydroxycinnamic acids underwent two stages: the rapid stage, above $70 \%$ decrease occurred at 21 days of incubation; the stable stage, the content of esterified hydroxycinnamic acids remained fairly stable for the period between 21 and 28 days incubation [21]. Although longer incubation time was employed in current study, similar trend was also observed. It indicated that all the necessary enzymes were probably produced to act on the target linkages and release hydroxycinnamic acids. In terms of ether bonds, the majority of the cell well phenolics was S-derived lignin unit (54.5\%-59.4\%) (Figure 1B), and the yields of monolignol derivatives were expectably decreased as incubation processed (Table 3). Despite the $\mathrm{S} / \mathrm{G}$ ratio almost maintained around 1.56 to 1.73 , the relative proportion of $\mathrm{H}$ unit was slightly reduced from $10.7 \%$ to $6.4 \%$. It could be speculated that the ligninolytic system produced by Trametes velutina D10149 non-selectively cleaved the ether bonds between lignin substructures, relatively preferring to the $\mathrm{H}$-derived lignin unit. The composition of the phenolic compounds was obtained from alkaline nitrobenzene oxidation, reflecting the structural features of the side chain and extent of carbon-carbon linkages presented in the lignin. As expect, the major products were identified to be syringaldehyde and vanillin in the sample $\mathrm{C}_{0}$, representing $49.4 \%$ and $31.9 \%$ of the phenolic compounds, respectively (Table 4). As the biodegradation of lignin component, the detectable phenolic acids and aldehydes were gradually reduced from 48.99 to $35.27 \mu \mathrm{g} / \mathrm{mg}$ (weight \% of cellulosic samples). Clearly, the structural alteration of lignin in white rot fungi biodegradation primarily involved a preferential degradation of syringyl units, evidenced by the decreased $\mathrm{S} / \mathrm{G}$ ratio from $1.55\left(\mathrm{C}_{0}\right)$ to $1.24\left(\mathrm{C}_{4}\right)$, to $1.21\left(\mathrm{C}_{8}\right)$, to 1.09 $\left(C_{12}\right)$, and to $1.08\left(C_{16}\right)$ (Figure $1 C$ ). Similar phenomena were observed on poplar biodegradation by Ke et al. [23]. Based on the analysis of many methods (CP/MAS, ATRFTIR, Py-GC/MS, etc.), they concluded that the preferential lignin degradation site was at the S-units. Tai et al. isolated the ether-insoluble fraction from birch wood decayed by the white rot fungus Phanerochaete chrysosporium, and also found that syringyl type substructures were more susceptible to oxidative cleavage of $\mathrm{C}_{\alpha}-\mathrm{C}_{\beta}$ bond than guaiacyl type substructure [24]. On the basis of the component identification, the lignin-peroxidase-initiated, one-electron-transferring enzyme-oxidation homolytically cleaved $C_{\alpha}-C_{\beta}$ bond to produce 4-O-alkylated vanillin/syringaldehyde, and then generated the corresponding vanillic/syringic acids through radical-intermediate-induced autoxidations [25]. However, the structural variation of lignin was too insignificant to be clearly reflected in the FTIR spectra (Figure 2), as well as its low signal intensity on the lignocellulosic material.

\section{Crytallinity and morphologic analysis}

Contrary to the conventional chemical analysis, FTIR spectroscopy has been used as a rapid technique for obtaining crystal information of cellulosic samples with advantages

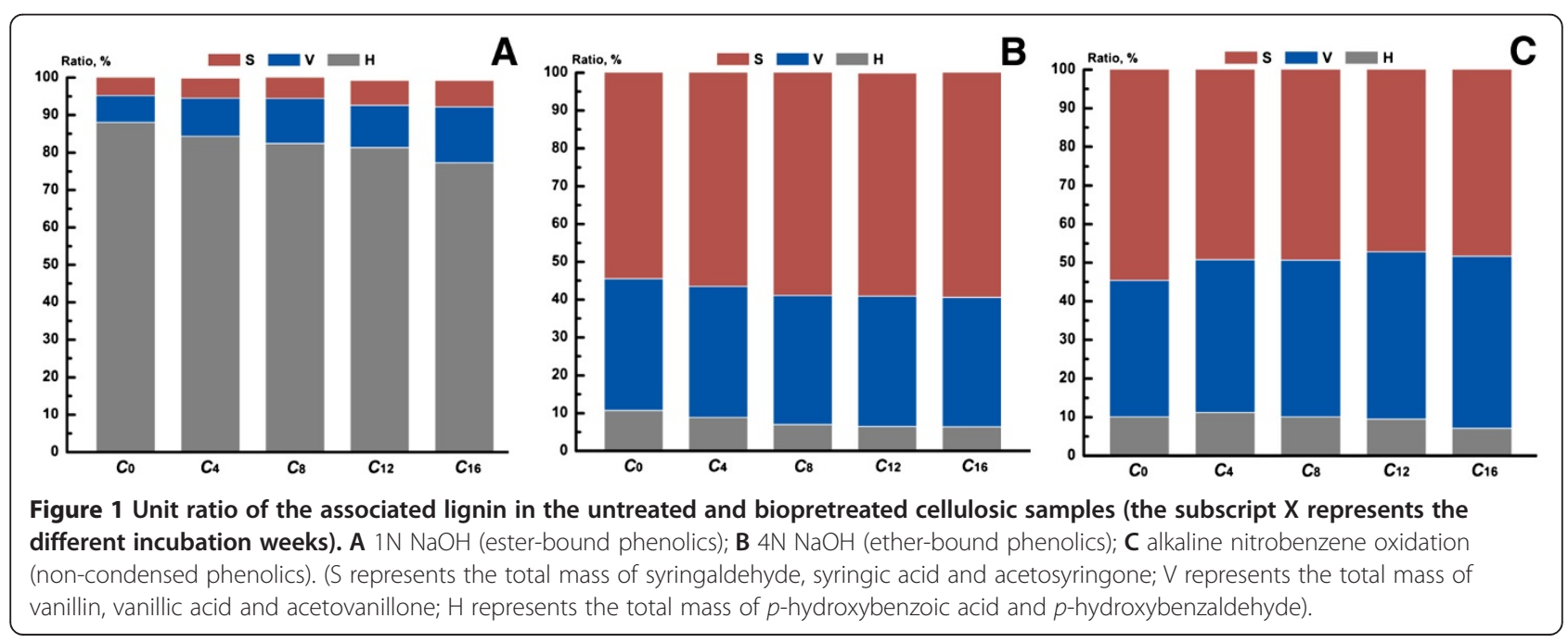


Table 2 Yields of monolignol derivatives $(w / w, \mu g / m g)^{a}$ of untreated and biopretreated cellulosic samples, obtained from $1 \mathrm{~N} \mathrm{NaOH}$ extraction at room temperature

\begin{tabular}{cccccc}
\hline Samples $^{\mathbf{b}}$ & $\boldsymbol{C}_{\mathbf{0}}$ & $\boldsymbol{C}_{\mathbf{4}}$ & $\boldsymbol{C}_{\mathbf{8}}$ & $\boldsymbol{C}_{\mathbf{1 2}}$ & $\boldsymbol{C}_{\mathbf{1 6}}$ \\
\hline$p$-hydroxybenzoic acid & 1.81 & 1.40 & 1.30 & 1.22 & 1.09 \\
\hline$p$-hydroxybenzaldehyde & 0.03 & $\mathrm{ND}^{\mathrm{c}}$ & 0.01 & $\mathrm{ND}$ & $\mathrm{ND}$ \\
\hline vanillic acid & 0.08 & 0.10 & 0.11 & 0.10 & 0.13 \\
\hline syringic acid & $\mathrm{ND}$ & $\mathrm{ND}$ & $\mathrm{ND}$ & $\mathrm{ND}$ & $\mathrm{ND}$ \\
\hline vanillin & 0.07 & 0.07 & 0.08 & 0.07 & 0.08 \\
\hline syringaldehyde & 0.11 & 0.09 & 0.09 & 0.10 & 0.10 \\
\hline Total & 2.09 & 1.66 & 1.59 & 1.50 & 1.41 \\
\hline
\end{tabular}

${ }^{\mathrm{a}}$ The standard deviations are less than $5 \%$; ${ }^{\mathrm{b}}$ Corresponding to the cellulosic residues in Table $1 ;{ }^{c}$ Not detectable.

of small sample requirement, short analysis time, and no destruction. Four peaks closely related to the crystal system and degree of intermolecular regularity were concerned, and two infrared ratios, $\alpha_{1437} \mathrm{~cm}^{-1} / \alpha_{899} \mathrm{~cm}^{-1}$ (lateral order index (LOI)) [26] and $\alpha_{1378} \mathrm{~cm}^{-1} / \alpha_{2900} \mathrm{~cm}^{-1}$ (total crystallinity index (TCI)) [27], were calculated and listed in Table 1, respectively. Hardly any difference was observed in all cellulosic samples, even when the incubation time had been prolonged to 16 weeks. The biodegradation of crystalline cellulose generally involves the action of both endoand exo-acting cellulases. When the brown-rot fungus (Fomitopsis palustris) was used to pretreat Cryptomeria japonica trees, the generated enzymes complex resulted in the obvious decrease of crystallinity from $48.9 \%$ to $9.1 \%$ after 12 weeks of incubation [28]. However, no data on cellulose crystallinity decrease by white-rot fungi was reported until now, indicating that the ligninolytic system of white rot fungi had a negligible effect on the crystalline cellulose. The $C r I$ values of all samples were also calculated from the corresponding XRD (Figure 3) and solid-state cross polarization/magic angle spinning nuclear magnetic resonance (CP/MAS NMR) patterns (data not shown), and the data were listed in Table 1 . As the data shown, it is in

Table 3 Yields of monolignol derivatives $(w / w, \mu g / m g)^{a}$ of untreated and biopretreated cellulosic samples, obtained from $4 \mathrm{~N} \mathrm{NaOH}$ extraction at $170^{\circ} \mathrm{C}$

\begin{tabular}{cccccc}
\hline Samples $^{\mathbf{b}}$ & $\boldsymbol{C}_{\mathbf{0}}$ & $\boldsymbol{C}_{\mathbf{4}}$ & $\boldsymbol{C}_{\mathbf{8}}$ & $\boldsymbol{C}_{\mathbf{1 2}}$ & $\boldsymbol{C}_{\mathbf{1 6}}$ \\
\hline$p$-hydroxybenzoic acid & 3.29 & 2.62 & 2.12 & 1.77 & 1.68 \\
\hline$p$-hydroxybenzaldehyde & 0.27 & 0.09 & 0.05 & 0.07 & 0.09 \\
\hline vanillic acid & 1.32 & 1.30 & 1.14 & 1.05 & 1.06 \\
\hline syringic acid & 1.27 & 1.27 & 1.02 & 1.03 & 1.08 \\
\hline vanillin & 9.47 & 8.38 & 8.41 & 8.04 & 7.94 \\
\hline syringaldehyde & 15.01 & 14.30 & 16.22 & 14.58 & 14.37 \\
\hline acetovanilline & 0.76 & 0.82 & 1.02 & 0.62 & 0.51 \\
\hline acetosyringone & 1.80 & 1.59 & 0.99 & 1.04 & 1.06 \\
\hline Total & 33.20 & 30.38 & 30.98 & 28.18 & 27.79 \\
\hline
\end{tabular}

${ }^{\mathrm{a}}$ The standard deviations are less than $5 \%$; ${ }^{\mathrm{b}}$ Corresponding to the cellulosic residues in Table 1.
Table 4 Yields of phenolic acids and aldehydes (w/w, $\mu \mathrm{g} / \mathrm{mg})^{\text {a }}$ from alkaline nitrobenzene oxidation of untreated and biopretreated cellulosic samples

\begin{tabular}{cccccc}
\hline Samples $^{\mathbf{b}}$ & $\boldsymbol{C}_{\mathbf{0}}$ & $\boldsymbol{C}_{\mathbf{4}}$ & $\boldsymbol{C}_{\mathbf{8}}$ & $\boldsymbol{C}_{\mathbf{1 2}}$ & $\boldsymbol{C}_{\mathbf{1 6}}$ \\
\hline$p$-hydroxybenzoic acid & 4.77 & 4.70 & 3.95 & 3.40 & 2.34 \\
\hline$p$-hydroxybenzaldehyde & 0.20 & 0.15 & 0.07 & 0.05 & 0.16 \\
\hline vanillic acid & 1.11 & 1.32 & 0.78 & 1.01 & 1.57 \\
\hline syringic acid & 2.22 & 2.30 & 1.72 & 1.69 & 2.20 \\
\hline vanillin & 15.63 & 15.90 & 15.40 & 14.40 & 14.18 \\
\hline syringaldehyde & 24.18 & 19.13 & 17.93 & 15.12 & 14.83 \\
\hline acetovanilline & 0.54 & ND $^{\boldsymbol{c}}$ & $\mathrm{ND}$ & 0.25 & $\mathrm{ND}$ \\
\hline acetosyringone & 0.34 & $\mathrm{ND}$ & $\mathrm{ND}$ & 0.26 & $\mathrm{ND}$ \\
\hline Total & 48.99 & 43.49 & 39.86 & 36.18 & 35.27 \\
\hline
\end{tabular}

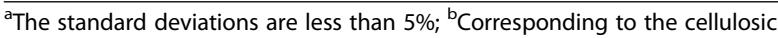
residues in Table $1 ;{ }^{c}$ Not detectable.

agreement with the conclusion from the FTIR analysis, and further confirmed that the crystallinity almost remained essentially the same in the biodegradation process.

The surface area is generally considered as important role in the accessibility and adsorption of enzymes. Clearly, the SEM images demonstrated that the biological pretreatment with white rot fungus Trametes velutina D10149 led to the evident damage on the intact cell structure (Figure 4), which will benefit for enhancing digestibility of pretreated poplar with SSF. The native material $\left(\mathrm{C}_{0}\right)$ displayed a regular and compact surface structure, the bast fibers arranged in bundles. After 8 weeks incubation, the apparent changes on surface were observed $\left(C_{8}\right)$, including the presence of cracks and ridges, the exposure of internal cell wall, and the disappearance of cohesion within the fibers. However, the penetration of cellulose fibers by hyphal was not obvious from SEM. Prolonging incubation period to 16 weeks $\left(C_{16}\right)$, the cell wall was further attached by the fungus or the extracellular enzymes secreted by the fungus, presenting more cracks and scars. Fibril separation was also observed since the degraded fibers were split in the direction of the fiber axis. Overall, it could be speculated that the defibrillation and delignification co-effect of biodegradation released a large reactive area on the fiber surface, consequently improving the accessibility of cellulose and the bioconversion efficiency.

\section{Products in SSF}

SSF was conducted to evaluate ethanol production from fungal pretreated poplar. In SSF, enzymatic hydrolysis and fermentation are run simultaneously, which has been shown to have several advantages over a separate process (separate hydrolysis and fermentation, SHF), including lower enzyme inhibition, less processing time, and higher ethanol yield [29]. Since enzymatic hydrolysis is the limiting factor in SSF at the low yeast concentration [30], the 


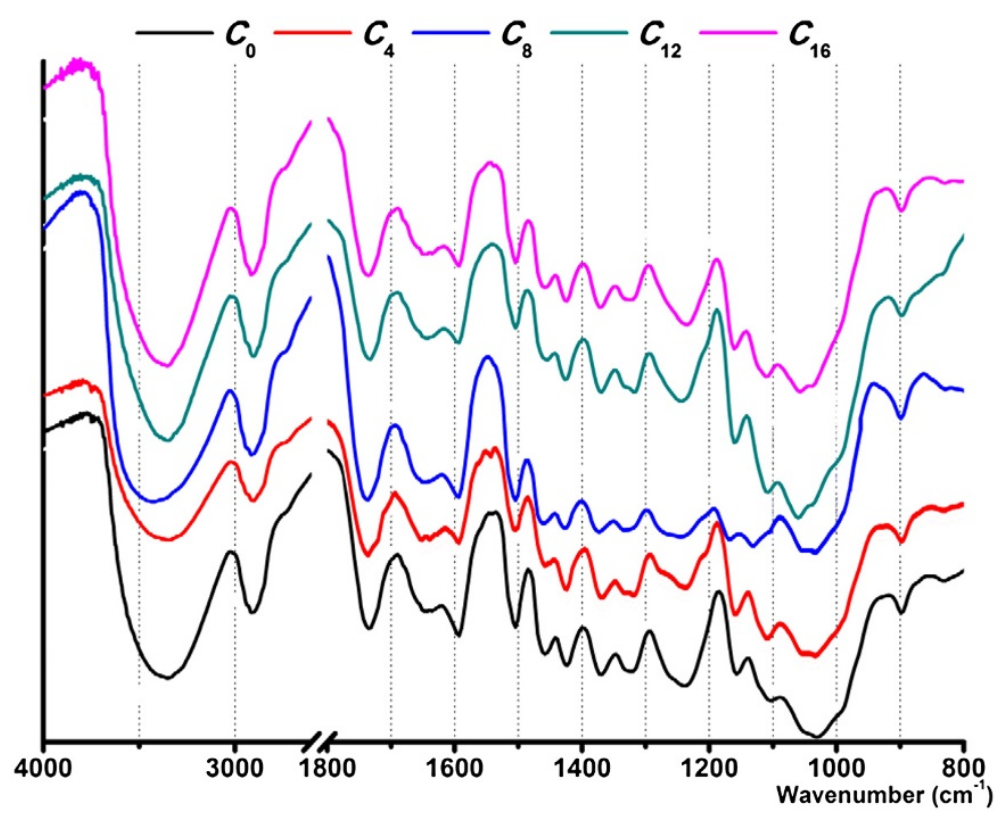

Figure 2 FTIR spectra of the untreated and biopretreated cellulosic samples (the subscript X represents the different incubation weeks).

concentrations of glucose and ethanol versus time were measured and shown in Figure 5. After $24 \mathrm{~h}$ of SSF, the highest ethanol yield (75\%) was reached from the cellulosic sample biodegraded for 16 weeks $\left(\mathrm{C}_{16}\right)$, which is equivalent to the ethanol concentration of $5.16 \mathrm{~g} / \mathrm{L}$ in the fermentation broth. From the raw poplar $\left(\mathrm{C}_{0}\right)$, the final concentration of ethanol was only $2.95 \mathrm{~g} / \mathrm{L}$, corresponding to less than $30 \%$ cellulose conversion. Clearly, prolonging incubation duration could gradually increase the cellulose conversion. This phenomenon was closely related to the partial removal of lignin and the modification of lignin macromolecules during the biodegradation treatment. Although the adsorption of cellulase on lignin significantly affects the enzymatic hydrolysis of cellulose, only $43 \%$ lignin removal is needed to render the biomass digestible [31]. Based on the ABSL results above, the relative content of lignin in the cellulosic samples just decreased from
$33.4 \%\left(\mathrm{C}_{0}\right)$ to $24.6 \%\left(\mathrm{C}_{16}\right)$. Thereby, the modification of lignin structure during fungal treatment undoubtedly played a key role in improving cellulose bioconversion rates. It could be speculated that the cleavage of ester and ether bonds probably decreased the hydrophobicity of lignin macromolecules and the unproductive binding of cellulase, correspondingly. Moilanen et al. treated the steam pretreated spruce with laccase and found that a lower amount of cellulases were adsorbed to lignin than the untreated sample [32]. Meanwhile, the partially blocking effects of lignin on the accessible pores and surfaces of cellulose were probably reduced by lignin removal with biodegradation. In addition, the decreasing trends of glucose concentration were similar, remaining less than $4.5 \mathrm{~g} / \mathrm{L}$ in the final broth. Combining with the weight losses [33], biodegradation with white-rot fungus Trametes velutina D10149 for 16 weeks was proved to be the best

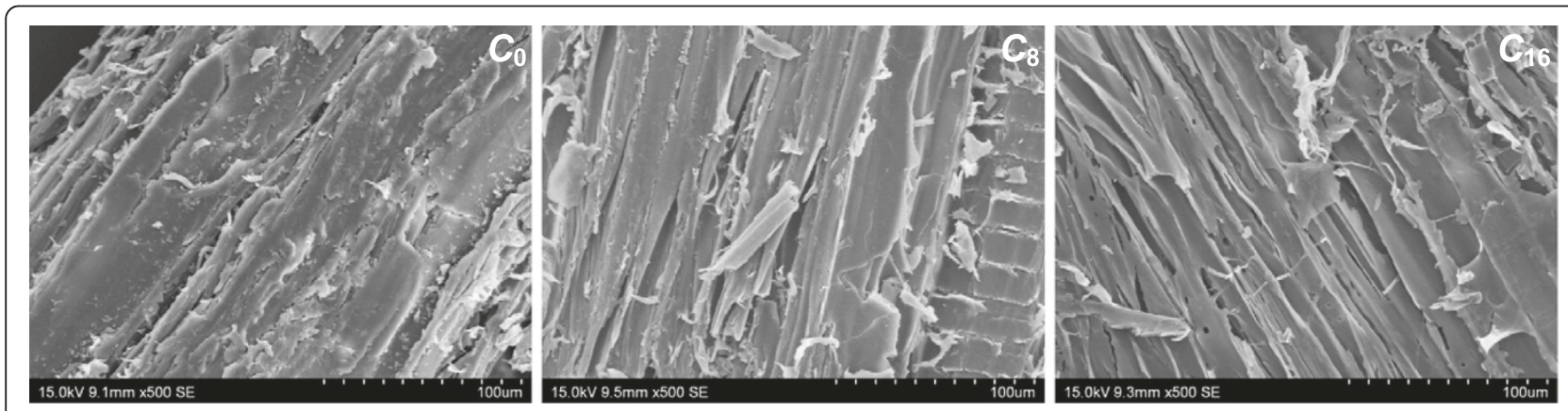

Figure 3 SEM micrographs $(\times 5 \mathbf{5 0 0})$. Control $\left(C_{0}>\right)$ and biopretreated poplar samples $\left(C_{8}\right.$ for 8 weeks incubation and $C_{16}$ for 16 weeks incubation) with $T$. velutina D10149. 


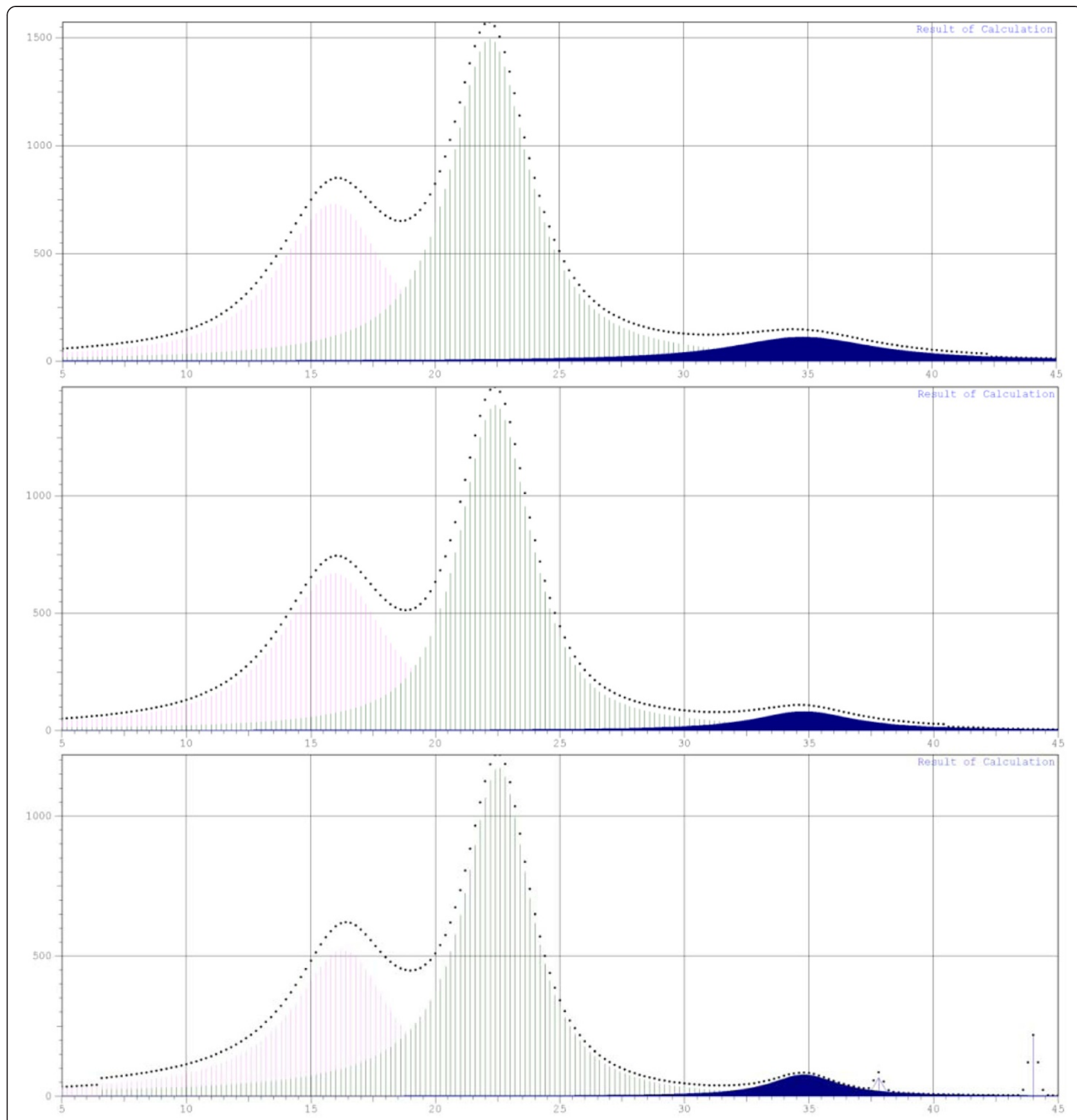

Figure 4 X-ray diffractograms. Untreated $\left(C_{0}\right)$ and fungal-pretreated $\left(C_{4}\right.$ for 4 weeks incubation and $C_{16}$ for 16 weeks incubation) poplar.

choice, achieving $34.8 \%$ cellulose utilization in poplar. Best conversion result obtained was $75 \%$ of the theoretical value, indicating that the process (biodegradation, delignification and/or saccharification/fermentation) should be optimized to achieve higher conversion rate in our future work.

\section{Conclusions}

Selective white rot fungus has shown potential for lignocelluloses pretreatment. In this study, a new fungal isolate, Trametes velutina D10149, was used in the biological pretreatment to enhance the digestibility of triploid poplar. Although no unique and significant selectivity for lignin degradation was observed in biodegradation process, the ethanol production was achieved $5.16 \mathrm{~g} / \mathrm{L}$ in the fermentation broth after $24 \mathrm{~h}$ SSF from fungal-pretreated poplar substrate. Based on wet-chemical analysis of remaining lignin, the structural variation in lignin macromolecules was important for improving lignocelluloses bioconversion efficiency. 


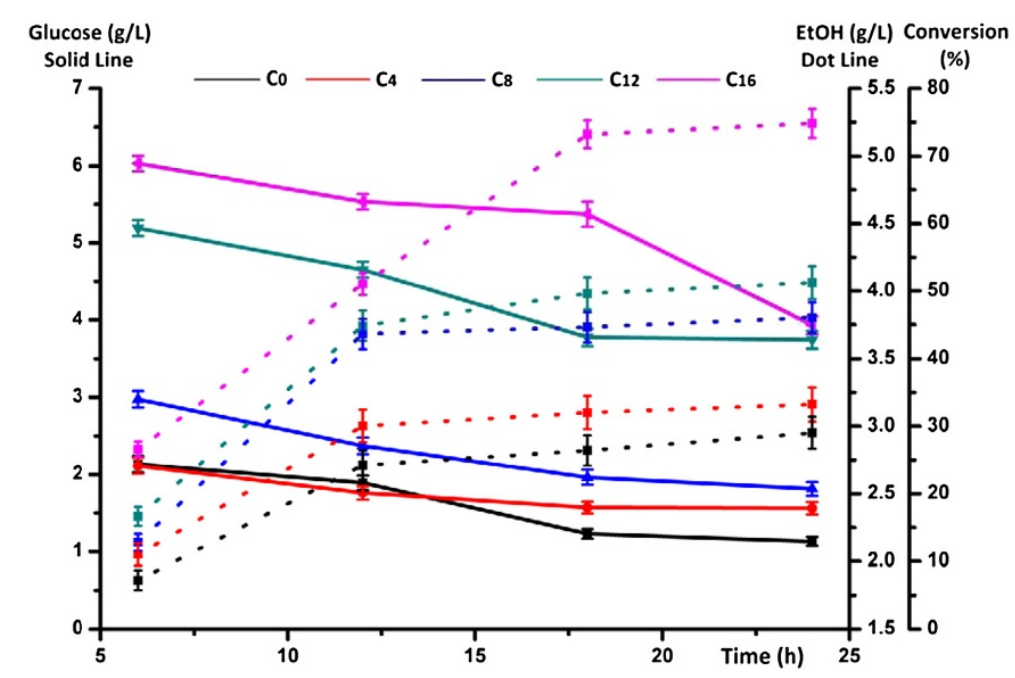

Figure 5 Time courses of glucose, ethanol yield ( $g / L$ ) and cellulose conversion (\%) during the simultaneous saccharification and fermentation (SSF) of untreated and biodegradation-treated poplar with white rot fungi Trametes velutina D10149.

\section{Methods}

Raw materials and chemicals

Triploid poplar (Populus tomentosa Carr.) of 3-year-old was cut from the suburb of Beijing, China. After being processed through a combination of chipping and milling, the fraction passing 40-mesh was collected and used throughout the study. The main components of the wood were determined as: glucose $44.4 \pm 0.6 \%$, xylose $23.0 \pm 0.5 \%$, Klason lignin $19.4 \pm 0.3 \%$, and acid soluble lignin $4.9 \pm 0.1 \%$ (weight \% of starting material). All chemicals are of analytical grade unless otherwise mentioned.

\section{Fungal strains and biopretreatment process}

The white rot fungus Trametes velutina D10149 was isolated from Jilin province in China, and preserved on $2 \%$ $(w / v)$ malt-extract agar (MEA) plates at $4^{\circ} \mathrm{C}$ in Institute of Microbiology, Beijing Forestry University. A plug of the fungi activated in $100 \mathrm{~mL}$ basic medium (containing glucose $20 \mathrm{~g} / \mathrm{L}$, yeast extract $5 \mathrm{~g} / \mathrm{L}, \mathrm{KH}_{2} \mathrm{PO}_{4} 1 \mathrm{~g} / \mathrm{L}$, $\mathrm{MgSO}_{4} 0.5 \mathrm{~g} / \mathrm{L}$, and $\mathrm{VB}_{1} 0.01 \mathrm{~g} / \mathrm{L}$ ). After been cultured on a rotary shaker at $28^{\circ} \mathrm{C}$ with a speed of $150 \mathrm{rpm}$, mycelial pellets were harvested after $5 \mathrm{~d}$ and mixed with $100 \mathrm{ml}$ distilled water. This suspension would act as inoculums.

The biological pretreatment with T. velutina D10149 was carried out in a 250-mL Erlenmeyer flask with $5 \mathrm{~g}$ of air-dried poplar and $12.5 \mathrm{~mL}$ of distilled water. The samples were sterilized in the autoclave for $20 \mathrm{~min}$ at $121^{\circ} \mathrm{C}$ and inoculated with $5 \mathrm{~mL}$ inoculums. The culture was incubated statically in $28^{\circ} \mathrm{C}$ for $4-16$ week. The non-inoculated sample was served as the control. All experiments were performed in triplicate.

\section{Enzyme and yeast}

The Cellulast 1.5L (cellulase) and Novozyme 188 ( $\beta$ glucosidase) were kindly provided by Novozymes Investment Co. Ltd. (Beijing, China). The microorganism used for fermentation was Saccharomyces cerevisiae in the form of dry yeast (thermal resistant) (Angel Yeast Company Ltd, Yichang, China). Dry yeast was activated in $2 \%$ glucose solution at $40^{\circ} \mathrm{C}$ for 20 minutes, then at $34^{\circ} \mathrm{C}$ for 2 hour.

\section{Evaluation of delignification and monolignol}

The associated lignin was analyzed through spectrophotometric method, which is easy and rapid for determining the total lignin concentration of a cell wall sample [19]. The procedure was described in detail in a previous paper [34], and the concentration of ABSL was calculated by adopting the appropriated absorption coefficient, $18.21 \mathrm{~mL}$ $\mathrm{mg}^{-1} \mathrm{~cm}^{-1}$ [35]. The ester-bound, ether-bound and noncondensed phenolics were analyzed with $1 \mathrm{~N} \mathrm{NaOH}$ at room temperature, $4 \mathrm{~N} \mathrm{NaOH}$ at $170^{\circ} \mathrm{C}$ and alkaline nitrobenzene oxidation processes, respectively. The separation and identification of phenolics was achieved with a HPLC system (1200 series, Agilent Technologies, USA) on a ZORBAX Eclipse XDB-C18 column $(4.6 \times 250 \mathrm{~mm})$ by comparison of retention times and UV spectra (DAD, diode array detector) of the eluting peaks and the authentic standard compounds (Sigma-Aldrich Corp.; St. Louis, MO, USA) [36].

\section{Structural characterization}

FTIR spectra of the cellulosic samples were recorded from an FTIR spectrophotometer (Tensor 27, Bruker, Germany) in the range 4000 to $800 \mathrm{~cm}^{-1}$, using a $\mathrm{KBr}$ disc containing $1 \%$ finely ground samples. Shimadzu 
XRD-6000 instrument (Japan) was used to examine the crystallinity, scanning from $5^{\circ}$ to $35^{\circ} 2 \theta$ by a goniometer at a scanning speed of $5 \% \mathrm{~min}$. The relative crystallinity is commonly measured as a ratio between the diffraction portion from the crystalline part of the sample and the total diffraction from the same sample. The surface characteristics of fungal treated substrates were observed by SEM, which was conducted with an S-3400N instrument (HITACHI, Japan) at acceleration voltages of $10 \mathrm{kV}$. Samples were firstly coated with gold-palladium in a sputter coater (E-1010, HITACHI, Japan).

\section{Simultaneous saccharification and fermentation}

The SSF experiments were performed under non-sterile conditions in $50 \mathrm{~mL}$ Erlenmeyer flasks sealed with a rubber stopper fitted with a one-way air valve to maintain an anaerobic environment. Each fermentation flask was composed of $0.5 \mathrm{~g}$ of untreated and fungal-treated substrates and $9 \mathrm{~mL}$ of nutrient medium, containing $10 \mathrm{~g} / \mathrm{L}$ yeast extract and $20 \mathrm{~g} / \mathrm{L}$ peptone in $50 \mathrm{mM}$ sodium acetate buffer ( $\mathrm{pH} 4.8)$. The insoluble substrates and the fermentation medium were sterilized at $121^{\circ} \mathrm{C}$ for $20 \mathrm{~min}$. Then, $30 \mathrm{FPU} / \mathrm{g}$ substrate of cellulase (Celluclast $1.5 \mathrm{~L}$ ), $60 \mathrm{IU} / \mathrm{g}$ substrate of $\beta$-glucosidase (Novozyme 188) and $3 \mathrm{~g} / \mathrm{L}$ yeast were added. Fermentation was carried out at $40^{\circ} \mathrm{C}$ for $24 \mathrm{~h}$ with shaking at $120 \mathrm{rpm}$. Aliquots of $0.5 \mathrm{~mL}$ were withdrawn and centrifuged at $10000 \mathrm{rpm}$ for $5 \mathrm{~min}$, and the supernatants were subjected to fermentation products analysis. All fermentations were performed in triplicate [37].

\section{Fermentation analysis}

Each sample was filtered through a $0.22 \mu \mathrm{m}$ filter and diluted appropriately with deionized water. Quantitative analysis for ethanol, glucose and xylose was performed on above HPLC system (1200 series, Agilent Technologies, USA) equipped with a refractive index detector. The separation was achieved using an Aminex HPX-42H column $(300 \times 7.8 \mathrm{~mm}$ i.d.; Bio-Rad Labs, Richmond, CA, USA) at $65^{\circ} \mathrm{C}$ with $4 \mathrm{mM} \mathrm{H}_{2} \mathrm{SO}_{4}$ as eluent at a flow rate of $0.6 \mathrm{~mL} / \mathrm{min}$. The cellulose conversion was calculated using the following formula [38]: $\%$ Cellulose Conversion $=\frac{[\mathrm{EtOH}]_{f-}[\mathrm{EtOH}]}{0.51(f[\text { Biosmass }] \times 1.111)} \times 100 \% 1$.

\section{Competing interests}

The authors declare that they have no competing interests.

\section{Authors' contributions}

KW and RS designed and coordinated the study, WW and HY carried out the experiments, and KW and $\mathrm{HY}$ analyzed the results. KW and $\mathrm{HY}$ wrote the paper, and RS reviewed the paper. All authors read and approved the final manuscript.

\section{Acknowledgements}

This work was supported by the grants from the Ministry of Science and Technology (973-2010CB732204) and the Fundamental Research Funds for the Central Universities (TD2011-11). Special thanks to Novozyme (China) Investment Co. Ltd. (Beijing) for their generous gift of cellulase and $\beta$ glucosidase. We also thank our colleagues for their valuable suggestions during the course of this work.

\section{Author details}

${ }^{1}$ Institute of Biomass Chemistry and Technology, Beijing Forestry University, Beijing, China. ${ }^{2}$ Institute of Microbiology, Beijing Forestry University, Beijing, China. ${ }^{3}$ State Key Laboratory of Pulp and Paper Engineering, South China University of Technology, Guangzhou, China.

Received: 30 October 2012 Accepted: 14 February 2013 Published: 21 March 2013

\section{References}

1. Perez J, Munoz-Dorado J, De-la-Rubia T, Martinez J: Biodegradation and biological treatment of cellulose, hemicellulose and lignin: an overview. Int Microbiol 2002, 5:53-63.

2. Agbor VB, Cicek N, Sparling R, Berlin A, Levin DB: Biomass pretreatment: fundamentals toward application. Biotechnol Adv 2011, 29:675-685.

3. Wang K, Jiang JX, Xu F, Sun RC: Influence of steaming explosion time on the physic-chemical properties of cellulose from Lespedeza stalks (Lespedeza crytoborya). Bioresour Technol 2009, 100:5288-5294.

4. Yang B, Wyman CE: Effect of xylan and lignin removal by batch and flow through pretreatment on enzymatic digestibility of corn stover cellulose. Biotechnol Bioeng 2004, 86:88-95.

5. Zavrel M, Bross D, Funke M, Buchs J, Spiess AC: High-throughput screening for ionic liquids dissolving (ligno-)cellulose. Bioresour Technol 2009, 100:2580-2587.

6. Zhu ZG, Sathitsuksanoh N, Vinzant T, Shell DJ, McMillan JD, Zhang Y-HP: Comparitive study of corn stover preteated by dilute acid and cellulose solvent-based lignocellulose fractionation: enzymatic hydrolysis, supramolecular structure, and substrate accessibility. Biotechnol Bioeng 2009, 103:715-724.

7. Kumar P, Barrett DM, Delwiche MJ, Stroeve P: Methods for pretreatment of lignocellulosic biomass for efficient hydrolysis and biofuel production. Ind Eng Chem Res 2009, 48:3713-3729.

8. Singh D, Zeng J, Laskar DD, Deobald L, Hiscox WC, Chen S: Investigation of wheat straw biodegradation by Phanerochaete chrysosporium. Biomass Bioenerg 2011, 35:1030-1040.

9. Dorado J, Van Beek TA, Claassen FW, Sierra-Alvarez R: Degradation of lipophilic wood extractive constituents in Pinus sylvestris by the white-rot fungi Bjerkandera sp. and Trametes versicolor. Wood Sci Technol 2001 35:117-125.

10. Martinez D, Larrondo LF, Putnam N, Gelpke MDS, Huang K, Chapman J, Helfenbein KG, Ramaiya P, Detter JC, Larimer F, Coutinho PM, Henrissat B, Berka R, Cullen D, Rokhsar D: Genome sequence of the lignocelluloses degrading fungus Phanerochaete chrysosporium strain RP78. Nat Biotechnol 2004, 22:695-700.

11. Singh D, Chen S: The white-rot fungus Phanerochaete chrysosporium: conditions for the production of lignin-degrading enzymes. Appl Microbiol Biotechnol 2008, 81:399-417.

12. Tien M, Kirk TK: Lignin-degrading enzyme from Phanerochaete chrysosporium: Purification, characterization, and catalytic properties of a unique $\mathrm{H}_{2} \mathrm{O}_{2}$-requiring oxygenase. Proc Natl Acad Sci U S A 1984, $81: 2280-2284$

13. Chen F, Dixon RA: Lignin modification improves fermentable sugar yields for biofuel production. Nat Biotechnol 2007, 25:759-761.

14. Dias AA, Freitas GS, Marques GSM, Sampaio A, Fraga IS, Rodrigues MAM, Evtuguin DV, Bezerra RMF: Enzymatic saccharification of biologically pre-treated wheat straw with white-rot fungi. Bioresour Technol 2010, 101:6045-6050.

15. Gupta R, Mehta G, Khasa YP, Kuhad RC: Fungal delignification of lignocellulosic biomass improves the saccharification of cellulosics. Biodegradation 2011, 22:797-804.

16. Baba $Y$, Tanabe $T$, Shirai $N$, Watanabe $T$, Honda $Y$, Watanabe $T$ : Pretreatment of Japanese cedar wood by white rot fungi and ethanolysis for bioethanol production. Biomass Bioenerg 2011, 35:320-324 
17. Keller FA, Hamilton JE, Nguyen QA: Microbial pretreatment of biomass: Potential for reducing severity of thermochemical biomass pretreatment. Appl Biochem Biotechnol 2003, 105-108:27-41.

18. Zhang $X, Y u H$, Huang $H$, Liu Y: Evaluation of biological pretreatment with white rot fungi for the enzymatic hydrolysis of bamboo culms. Int Biodeterior Biodegrad 2007, 60:159-164.

19. Fukushima RS, Hatfield RD: Comparison of the acetyl bromide spectrophotometric method with other lignin methods for determining lignin concentration in forage samples. J Agric Food Chem 2004, 52:3713-3720.

20. Zhang L, Li D, Wang L, Wang T, Zhang L, Chen XD, Mao Z: Effect of steam explosion on biodegradation of lignin in wheat straw. Bioresour Technol 2008, 99:8512-8515.

21. Dinis MJ, Bezerra RMF, Nunes F, Dias AA, Guedes CV, Ferreira LMM, Cone JW, Marques GSM, Barros ARN, Rodrigues MAM: Modification of wheat straw lignin by solid state fermentation with white-rot fungi. Bioresour Technol 2009, 100:4829-4835.

22. Chua MGS, Wyman M: Characterization of autohydrolysis aspen (P. tremuloides) lignin. Part 1. Composition and molecular weight distribution of extracted autohydrolysis lignin. Can J Chem 1979, 57:1141-1149.

23. Ke J, Laskar DD, Chen S: Biodegradation of hardwood lignocellulosics by the western poplar clearwing borer, Paranthrene robiniae (Hy. Edwards). Biomacromolecules 2011, 12:1610-1620.

24. Tai $D$, Terazawa $M$, Chen $C L$, Chang HM: Lignin biodegradation products from birch wood by Phanerochaete chrysosporium. Part 1. Fractionation of methanol-extractive and characterization of ether-insoluble lowmolecular-weight fraction. Holzforschung 1990, 44:185-190.

25. Tai $D$, Terazawa $M$, Chen $C L$, Chang HM: Lignin biodegradation products from birch wood decayed by Phanerochaete chrysosporium. Part 2. The constituents of ether-soluble low-molecular-weight fractions. Holzforschung 1990, 44:257-262.

26. O'Conner RT, DuPer EF, Mitcham D: Application of infrared absorption spectroscopy to investigations of cotton and modified cottons. Part I: physical and crystalline modifications and oxidation. Text Res J 1958, 28:382-392.

27. Nelson ML, O'Connor RT: Relation of certain infrared bands to cellulose crystallinity and crystal lattice type. Part II. A new infrared ratio for estimation of crystallinity in cellulose I and II. J Appl Polym Sci 1964, 8:1325-1341.

28. Yoon JJ, Kim YK: Degradation of Crystalline Cellulose by the Brown-rot Basidiomycete Fomitopsis palustris. J Microbiol 2005, 43:487-492.

29. Wingren A, Galbe M, Zacchi G: Techno-economic evaluation of producing ethanol from softwood: a comparison of SSF and SHF and identification of bottlenecks. Biotechnol Prog 2003, 19:1109-1117.

30. Linde M, Jakobsson EL, Galbe M, Zacchi G: Steam pretreatment of dilute $\mathrm{H}_{2} \mathrm{SO}_{4}$-inpregnated wheat straw and SSF with low yeast and enzyme loading for bioethanol production. Biomass Bioenerg 2008, 32:326-332.

31. Chang VS, Holtzapple MT: Fundamental factors affecting biomass enzymatic reactivity. Appl Biochem Biotechnol 2000, 84:5-37.

32. Moilanen U, Kellock M, Galkin S, Viikari L: The laccase-catalyzed modification of lignin for enzymatic hydrolysis. Enzyme Microb Technol 2011, 49:492-498.

33. Yang HY, Wang K, Wang W, Xu F, Sun RC: Improved bioconversion of poplar by synergistic treatments with white-rot fungus Trametes velutina D10149 pretreatment and alkaline fractionation. Bioresour Technol 2012. http://dx.doi.org/10.1016/j.biortech.2012.12.103.

34. Wang K, Yang HY, Guo SH, Tang Y, Jiang JX, Xu F, Sun RC: Organosolv fractionation process with various catalysts for improving bioconversion of triploid poplar. Process Biochem 2012, 47:1503-1509.

35. Foster CE, Martin TM, Pauly M: Comprehensive compositional analysis of plant cell walls (lignocellulosic biomass) Part I: Lignin. J Vis Exp 2010, 37:1745. doi:10.3791/1745.

36. Wang $K$, Yang HY, Yao $X, X u$ F, Sun RC: Structural transformation of hemicelluloses and lignin from triploid poplar during acidpretreatment based biorefinery process. Bioresour Technol 2012, 116:99-106.

37. Sasaki, , Takada $R$, Watanabe $T$, Honda $Y$, Karita S, Nakamura $Y$, Watanabe $T$ : Surface carbohydrate analysis and bioethanol production of sugarcane bagasse pretreated with the white rot fungus, Ceriporiopsis subvermispora and microwave hydrothermolysis. Bioresour Technol 2011, 102:9942-9946.

38. Dowe N, McMillan J: SSF experimental protocols — lignocellulosic biomasshydrolysis and fermentation. National Renewable Energy Laboratory: Laboratory Analytical Procedure (LAP) 2008. http://www.nrel.gov/docs/gen/ fy13/42618.pdf.

doi:10.1186/1754-6834-6-42

Cite this article as: Wang et al.: Structural evaluation and bioethanol production by simultaneous saccharification and fermentation with biodegraded triploid poplar. Biotechnology for Biofuels 2013 6:42.

\section{Submit your next manuscript to BioMed Central and take full advantage of:}

- Convenient online submission

- Thorough peer review

- No space constraints or color figure charges

- Immediate publication on acceptance

- Inclusion in PubMed, CAS, Scopus and Google Scholar

- Research which is freely available for redistribution 